\title{
Distributional Changes in U.S. Sugar-Sweetened Beverage Purchases, 2002-2014
}

\author{
Pourya Valizadeh, PhD, ${ }^{1}$ Barry M. Popkin, PhD, ${ }^{1,2}$ Shu Wen Ng, PhD ${ }^{1,2}$
}

\begin{abstract}
Introduction: U.S. policy actions focus on reducing sugar-sweetened beverage purchases. Yet, there are no studies on trends in overall purchase distribution and how it has changed by key subpopulations. This study examined changes in distributions of total sugar-sweetened beverage purchases and its major subtypes (regular carbonated soft drinks and fruit/sports/energy drinks) in 2002-2014 and distinguished among low, moderate, and high purchasers.
\end{abstract}

Methods: Longitudinal data on sugar-sweetened beverage purchases of U.S. households from the 2002-2014 Nielsen Homescan Panel were used. Sugar-sweetened beverages were defined as all caloric non-alcoholic beverages containing added sugars. Longitudinal quantile regression model examined trends across distributions (from quantile 25 to 95) of purchases (measured in $\mathrm{kcal} /$ day/ capita), while accounting for households' unobserved differences. All statistical analyses were conducted in 2019.

Results: All households across the total purchase distribution significantly reduced their purchases. High purchasers made less proportional reductions than low purchasers (e.g., 35\% at 95th quantile vs $62 \%$ at 25 th quantile). However, the smaller relative reductions among higher purchasers translated into larger absolute decreases (e.g., $134 \mathrm{kcal} /$ day/capita at 95th quantile vs $23 \mathrm{kcal} /$ day/capita at 25th quantile). Similar patterns in heterogeneity were observed across sugar-sweetened beverage subtype distributions and among racial/ethnic and income groups. In addition, there were significant racial/ethnic and income disparities in total sugar-sweetened beverage purchases in 2002-2003. Although racial/ethnic disparities among higher purchasers improved, income disparity patterns at all purchase levels persisted into 2013-2014.

Conclusions: From 2002-2003 to 2013-2014, U.S. households at all purchase levels made meaningful reductions in sugar-sweetened beverage purchases in both absolute and relative terms. Furthermore, racial/ethnic disparities in total sugar-sweetened beverage purchases narrowed, but income disparity patterns persisted.

Am J Prev Med 2020;59(2):260-269.

\section{INTRODUCTION}

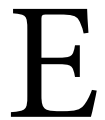

xcessive consumption of sugar-sweetened beverages (SSBs) has been linked to increased risk of obesity and diet-related noncommunicable diseases. $^{1-7}$ This association is not surprising as SSBs are the single largest source of added sugar in the U.S. diet. ${ }^{8-10}$ In addition, studies have documented disproportionate effects of obesity and related noncommunicable diseases on racial/ethnic minorities and low-SES groups, along with persistently higher SSB intake among non-Hispanic black (NHB) and low-income subpopulations. ${ }^{11-14}$ Strategies aimed at discouraging SSB consumption in the U.S. have been gaining momentum, ${ }^{15-18}$ making surveillance on

From the ${ }^{1}$ Carolina Population Center, University of North Carolina at Chapel Hill, Chapel Hill, North Carolina; and ${ }^{2}$ Department of Nutrition, Gillings School of Global Public Health, University of North Carolina at Chapel Hill, Chapel Hill, North Carolina

Address correspondence to: Pourya Valizadeh, PhD, Carolina Population Center, University of North Carolina at Chapel Hill, CB \#8120 University Square, 123 West Franklin Street, Chapel Hill NC 27516.

E-mail: pouryav@email.unc.edu.

0749-3797/ $\$ 36.00$

https://doi.org/10.1016/j.amepre.2020.02.002 
trends in SSB consumption an integral part of public health efforts.

Several studies have focused on examining trends in the mean SSB consumption and purchases. ${ }^{19-23}$ These studies revealed that mean SSB consumption and purchases have fallen since 2002-2003, but it is critical to determine the extent to which observed reductions are from different types of consumers. Higher SSB consumers who are at elevated risk of cardiometabolic consequences of excessive sugar or energy intake are of key concern. Indeed, reductions in consumption among high-SSB consumers could have the most meaningful impact on curbing the obesity epidemic. Yet, studies investigating trends across the SSB consumption distribution are rare, ${ }^{11,13}$ and studies exploring trends along the SSB purchase distribution are nonexistent.

The primary purpose of this study was to examine trends at different points across distributions of total SSB purchases and its key subtypes (regular carbonated soft drinks [RCSDs] and fruit/sports/energy drinks) in the U.S. from 2002-2003 to 2013-2014 overall and across racial/ethnic and income subpopulations. Put differently, this study explored how SSB purchases of low, moderate, and high purchasers have changed over time. Drawing on longitudinal data on households' SSB purchases, this study improves on earlier cross-sectional analyses of trends in SSB consumption ${ }^{11,13,19-23}$ by accounting for both observable and unobservable differences among households through a longitudinal quantile regression model. ${ }^{24,25}$ To further inform public health policy efforts, this study also investigated how and whether racial/ethnic and income disparity patterns in SSB purchases have changed over time.

\section{METHODS}

This study used data from the 2002-2014 Nielsen Homescan Panel (Homescan), a nationwide consumer panel maintained by the Nielsen Company. ${ }^{26}$ Homescan is a longitudinal householdlevel data set containing product-level information on all packaged food/beverage purchases for at-home consumption. Households are recruited from 52 metropolitan and 24 nonmetropolitan areas and instructed to scan the Universal Product Codes of all packaged foods/beverages using scanners/smartphone applications immediately upon returning home from a grocery shopping trip. This information is uploaded to Nielsen through Internet/landline phone weekly. Each year, Nielsen prepares a static panel, including households that consistently reported purchases during $\geq 10$ months of the previous calendar year. These static panel data are used in academic studies (e.g., to analyze food demand/consumption), including this study. ${ }^{27-32}$ Some studies investigating the representativeness of Homescan have reported some sample-selection or sample-participation biases, ${ }^{33}$ which can be adjusted for using household demographics. ${ }^{29}$
In the static panel, each transaction record contains data on quantity purchased, dollars paid, product attributes, Universal Product Code, and Homescan product module code. To obtain calorie/ingredient information needed in the construction of outcomes of interest in this study, Homescan purchase data were merged (by Universal Product Codes and year) to Nutrition Facts Panel and ingredient data from a variety of sources, including Mintel Global New Product Database. ${ }^{34}$

\section{Study Sample}

Homescan annually collects sociodemographic information including income, educational attainment, race/ethnicity, age and gender of all household members, and household sampling weights. This study sample was restricted to non-Hispanic white (NHW), NHB, and Hispanic households with $\geq 2$ years of data. Moreover, households were defined as low income if income was $\leq 185 \%$ of the federal poverty line, middle income if income was $>185 \%$ and $\leq 400 \%$ of the federal poverty line, and high income if income was $>400 \%$ of the federal poverty line, as done elsewhere. ${ }^{13,35}$

The analysis sample included 111,397 households. For these households, weekly food/beverage purchases were aggregated to a household-year level $(n=634,783)$. Table 1 shows sample descriptive statistics, overall and across 5 periods from 2002 to 2014. Although there were some minor differences in household characteristics across time, such differences were not problematic as the empirical model accounted for households-observed and -unobserved differences.

\section{Measures}

Using Homescan product module codes and nutrient information, the total SSB category was defined to include all caloric non-alcoholic beverages containing added sugars, namely RCSDs, non- $100 \%$ fruit/vegetable drinks/juices, sports/energy drinks, sweetened tea/ coffee/dairy drinks, and beverage powder/concentrates. In addition, RCSDs and fruit/sports/energy drinks were considered 2 key SSB subcategories. Using calorie information and total yearly SSB purchases of households, daily per capita calorie (kcal/day/capita) purchases from these SSB categories were calculated and used as outcomes of interest. In this study's data, RCSDs and fruit/sports/ energy drinks on average accounted for approximately $70 \%$ of total SSB calories ( $47 \%$ and $23 \%$, respectively). All other SSBs combined accounted for the remaining $30 \%$.

\section{Statistical Analysis}

In this analysis, different types of SSB-purchasing households were defined by quantiles of SSB purchase distributions; low purchasers were defined by low quantiles and high purchasers by high quantiles. For instance, one may think of a household at 25th quantile of the total SSB purchase distribution as a low purchaser, whereas a household at 95th quantile could be considered a high purchaser. Thus, a specific quantile is not strictly assigned to a specific type of consumer, and it is the relative position of households along the distribution that matters.

In this context, quantile regression ${ }^{36-38}$ was used to analyze trends at quantiles 25-95 (in 10-unit increments) of total SSB, RCSD, and fruit/sports/energy drink distributions. Detailed descriptions of empirical models and estimation approaches are provided in the Appendix (available online). Briefly, main variables in the 
Table 1. Household Summary Statistics, Overall and for 5 Periods Over 2002-2014

\begin{tabular}{|c|c|c|c|c|c|c|}
\hline \multirow[b]{2}{*}{ Variable } & \multirow{2}{*}{$\begin{array}{l}\text { Full sample } \\
2002-2014\end{array}$} & \multicolumn{5}{|c|}{ By period } \\
\hline & & 2002-2003 & 2004-2006 & 2007-2009 & 2010-2012 & 2013-2014 \\
\hline Household size & $2.49(1.42)$ & $2.48(1.41)$ & $2.50(1.42)$ & $2.49(1.43)$ & $2.50(1.43)$ & $2.46(1.42)$ \\
\hline Household with children, $\%$ & $33.03(47.03)$ & $32.79(46.95)$ & $34.31(47.47)$ & $34.42(47.51)$ & $32.58(46.87)$ & $29.83(45.75)$ \\
\hline Household head's age, year & $53.42(14.50)$ & $53.33(14.67)$ & $52.91(14.77)$ & $52.77(14.63)$ & $53.60(14.30)$ & $55.03(13.91)$ \\
\hline Married household head, \% & 47.85 (49.95) & 49.11 (49.99) & $47.60(49.94)$ & $45.61(49.81)$ & $47.42(49.93)$ & $51.30(49.98)$ \\
\hline \multicolumn{7}{|l|}{ Household head's race, \% } \\
\hline NHW & $76.97(42.10)$ & $79.64(40.27)$ & $77.82(41.55)$ & $76.76(42.24)$ & $75.85(42.80)$ & $75.21(43.18)$ \\
\hline NHB & $11.83(32.30)$ & $11.29(31.64)$ & $11.71(32.15)$ & $11.77(32.22)$ & $12.04(32.54)$ & $12.30(32.84)$ \\
\hline Hispanic & $11.20(31.54)$ & $9.07(28.72)$ & $10.47(30.62)$ & $11.47(31.87)$ & $12.11(32.62)$ & $12.50(33.07)$ \\
\hline \multicolumn{7}{|l|}{ Household's income level, \% } \\
\hline Low income & $25.75(43.73)$ & $21.16(40.85)$ & $24.83(43.20)$ & $26.02(43.87)$ & $26.75(44.27)$ & $29.53(45.62)$ \\
\hline Middle income & $36.92(48.26)$ & $41.10(49.20)$ & $34.30(47.47)$ & $36.84(48.24)$ & $38.16(48.58)$ & $35.10(47.73)$ \\
\hline High income & $37.33(48.37)$ & $37.74(48.47)$ & $40.87(49.16)$ & $37.15(48.32)$ & $35.09(47.72)$ & $35.37(47.81)$ \\
\hline \multicolumn{7}{|c|}{ Household head's education, \% } \\
\hline Less than high school & $35.36(47.81)$ & $34.76(47.62)$ & $35.44(47.83)$ & $35.89(47.97)$ & $35.31(47.79)$ & 35.06 (47.71) \\
\hline High school & $23.76(42.56)$ & $22.76(41.93)$ & $24.24(42.85)$ & $23.77(42.57)$ & $24.13(42.79)$ & $23.37(42.32)$ \\
\hline Some college & $20.00(40.00)$ & $21.92(41.37)$ & $20.13(40.10)$ & $19.54(39.65)$ & $19.43(39.57)$ & $19.61(39.70)$ \\
\hline College degree or more & $20.88(40.65)$ & $20.56(40.42)$ & $20.19(40.14)$ & $20.80(40.58)$ & $21.14(40.83)$ & $21.97(41.41)$ \\
\hline Observations & 634,783 & 68,154 & 134,814 & 164,847 & 163,534 & 103,434 \\
\hline
\end{tabular}

Source: Authors' calculations were based, in part, on data reported by Nielsen through its Homescan Services for all food categories, including beverages and alcohol for the 2002-2014 periods across the U.S. market. ${ }^{26}$ The conclusions drawn from the Nielsen data are those of the authors and do not reflect the views of Nielsen. Nielsen is not responsible for, had no role in, and was not involved in analyzing and preparing the results reported herein.

Note: SDs are in parentheses. Low-income households are defined as those with annual income $\leq 185 \%$ of the FPL, middle-income households as those with income between $185 \%$ and $400 \%$ of the FPL, and high-income households as those with income $>400 \%$ of the FPL. Survey weights were applied.

NHB, non-Hispanic black; FPL, federal poverty line; NHW, non-Hispanic white.

model were 4 indicator variables for 5 periods from 2002 to 2014 : 2002-2003, 2004-2006, 2007-2009, 2010-2012, and 2013-2014, with 2002-2003 set as reference. Other (time-variant) model covariates were variables for proportions of household members within 10 gender-specific age groups to account for household composition, indicator variables for household income, and indicator variables for household head's marital status and educational attainment.

To account for time-invariant unobserved household characteristics, a correlated random effects quantile regression estimator was used. $^{24,25,39}$ Coefficient estimates for period indicators captured the magnitudes of absolute changes (kcal/day/capita) in SSB purchases from 2002-2003 to the period they represented. For instance, the 2013-2014 coefficient was interpreted as the absolute change in SSB purchases from 2002-2003 (baseline) to 2013-2014. Therefore, comparing the magnitudes of coefficient estimates of the 2013 -2014 indicator at different quantiles of (each) SSB purchase distribution would reveal whether low-, moderate-, and high-SSB purchasers reduced their purchases differently from 2002-2003 to 2013 -2014. Using absolute changes and adjusted baseline SSB purchases, relative (percentage) changes were calculated.

To investigate differential trends by race/ethnicity, the analysis of the U.S. population was extended by including 2-way interaction terms between race/ethnicity indicators and all model covariates (Appendix, available online). A similar approach was used to explore differential trends among income groups. Finally, to examine whether racial/ethnic and income disparity patterns in
SSB purchases (i.e., relative differences between subpopulations) at baseline persisted over time, the existence of such disparities was first explored by testing the equality of purchase distributions between racial/ethnic groups and similarly, between income groups in 2002-2003. Then, tests of statistical differences between the magnitudes of relative changes in purchases of racial/ethnic groups and of income groups were conducted. As relative changes accounted for differences in baseline purchases across subpopulations (if any), rejecting the null hypothesis of equality of relative changes (across subpopulations) indicated that disparity patterns in 2013-2014 were different from those in 2002-2003. Statistical analyses were done in 2019 using Stata, version 15.1. SEs were clustered at the household-level.

\section{RESULTS}

Trends representative of the U.S. for total SSB purchase distribution are shown in Figure 1. Top panel shows the adjusted number of SSB calories purchased (kcal/day/capita) at different quantiles/periods. Middle and bottom panels display the estimated reductions in purchases (accompanied by 95\% CIs) at different quantiles from 2002-2003 to 2013-2014 in absolute and relative terms (solid lines), respectively. For comparison, mean absolute and relative declines are also displayed (dashed lines). 


\section{Total Sugar-Sweetened Beverages}
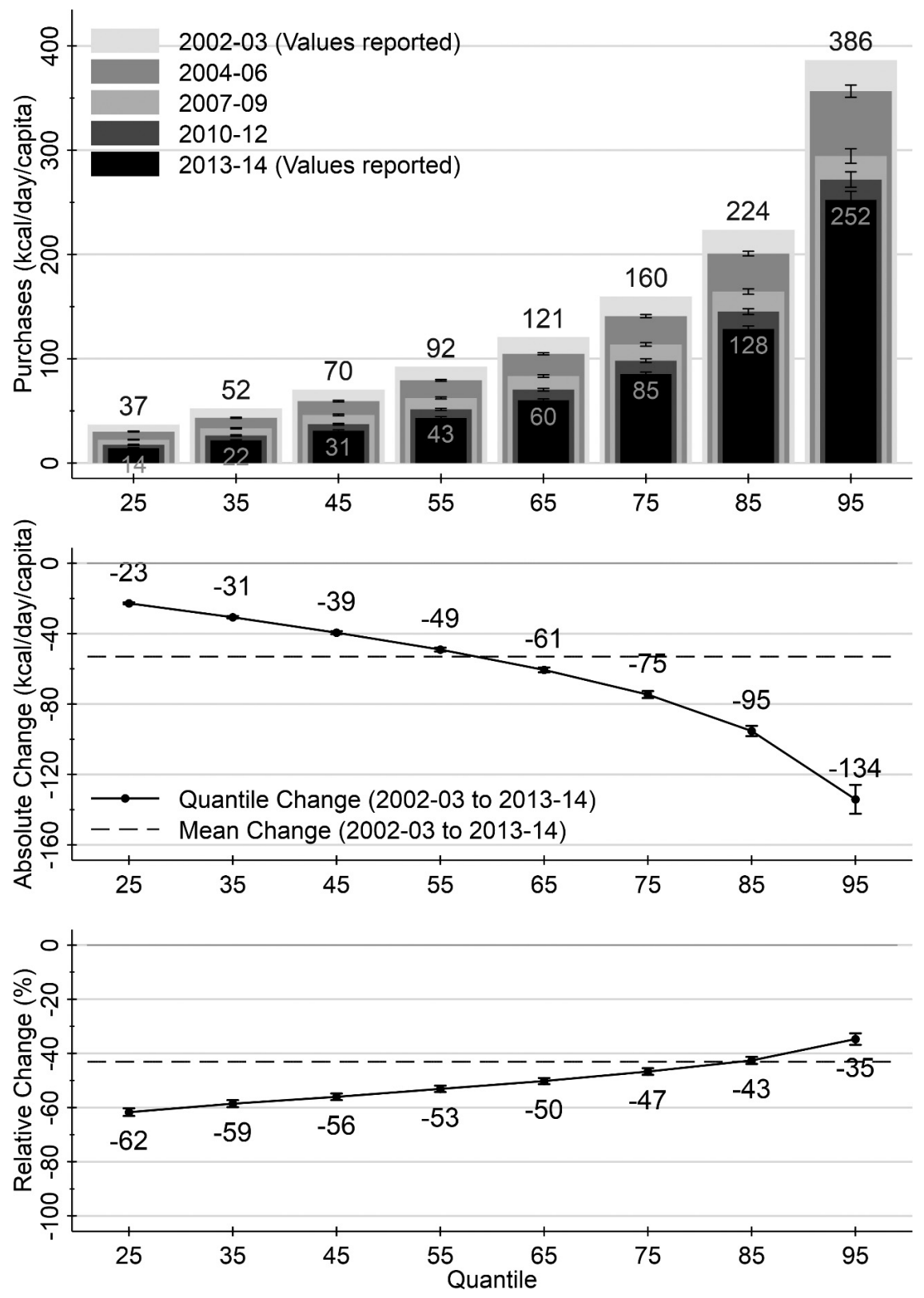

Figure 1. Trends across the adjusted distribution of total SSB purchases across all households from 2002-2003 to 2013-2014. Source: Authors' calculations were based, in part, on data reported by Nielsen through its Homescan Services for all food categories, including beverages and alcohol for the 2002-2014 periods across the U.S. market. ${ }^{26}$ The conclusions drawn from the Nielsen data are those of the authors and do not reflect the views of Nielsen. Nielsen is not responsible for, had no role in, and was not involved in analyzing and preparing the results reported herein. Note: The top panel displays households' total SSB purchases (kcal/day/capita) across the purchase distribution from quantiles 25th to 95th in 10-unit increments for 5 periods from 2002-2003 to 2013-2014. The middle panel shows the absolute quantile reductions (solid line) and mean reduction (dashed line) in total SSB purchases (kcal/day/capita) from 2002-2003 to 2013-2014. The bottom panel shows reductions in relative (percentage) terms. Survey weights were applied. All estimates are accompanied by $95 \%$ Cls calculated using SEs clustered at the household-level.

SSB, sugar-sweetened beverage.

First, there was important heterogeneity in terms of total SSB purchase level across the distribution (Figure 1, top panel). In 2002-2003, households at 95th quantile purchased about 10 times as many SSB calories as those at 25 th quantile (386 vs $37 \mathrm{kcal} /$ day/capita; $p<0.05$ ). Second, although households at all quantiles continually and gradually reduced their purchases from 2002-2003 to 2013-2014 (top panel), absolute reductions at higher 
quantiles were larger than at lower quantiles (middle panel). Thus, absolute reductions in purchases were not uniformly distributed between low and high purchasers as implied by the mean estimate; low purchasers reduced their SSB purchases less than the average consumer, whereas high purchasers reduced more. For instance, households at 25th and 95th quantiles decreased their purchases by 23 and $134 \mathrm{kcal} /$ day/capita $(p<0.05)$, respectively, whereas the average household made a 53 $\mathrm{kcal} /$ day/capita reduction $(p<0.05)$.

As shown at the bottom panel of Figure 1, the relative changes in total SSB purchases revealed a different heterogeneity pattern. Unlike the size of absolute reductions, which increased with quantile, relative reductions in SSB purchases were larger at lower quantiles and became smaller toward higher quantiles (e.g., $62 \%$ at 25 th quantile vs $35 \%$ at 95 th quantile; $p<0.05$ ). This pattern indicated that increases in magnitudes of absolute reductions toward higher quantiles (23 to $134 \mathrm{kcal} /$ day/capita) were less proportional than increases in baseline SSB purchases (37 to $386 \mathrm{kcal} /$ day/capita), leading to smaller relative reductions toward the distribution's right tail.

Similar heterogeneity patterns were observed across RCSD and fruit/sports/energy drink distributions (Appendix Figure 1, available online). In particular, the highest RCSD purchasers reduced purchases by $87 \mathrm{kcal} /$ day/capita (225 to $138 \mathrm{kcal} /$ day/capita, $p<0.05)$, and the highest fruit/sports/energy drink purchasers made a 37 $\mathrm{kcal} /$ day/capita reduction $(90$ to $53 \mathrm{kcal} /$ day/capita, $p<0.05)$. These results suggested that reductions along both RCSD and fruit/sports/energy drink distributions contributed to total SSB purchase distribution's shift. However, one should be cautious when drawing conclusions about the relative contribution of SSB subtypes to observed reductions in total SSB purchases because households at a certain quantile of the total SSB distribution may not necessarily be at the same quantile of its subtype distributions. For example, a household at 95th quantile of the total SSB distribution might be at 90th quantile of RCSD distribution and at 85th quantile of fruit/sports/energy drink distribution. However, the mean reduction of $53 \mathrm{kcal} /$ day/capita in total SSB purchases can be explained by a $30 \mathrm{kcal} /$ day/capita decrease in RCSDs, $12 \mathrm{kcal} /$ day/capita in fruit/sports/energy drinks, and $11 \mathrm{kcal} /$ day/capita in other SSBs.

Trends across the distribution of total SSBs by race/ ethnicity are shown in Figure 2. For simplicity, only adjusted purchases in 2002-2003 and 2013-2014 (top panels) and absolute reductions (bottom panels) are reported. First, there are significant racial/ethnic disparities in total SSB purchases at baseline. Importantly, NHB households purchased more SSB calories than NHWs and Hispanics at all points across the distribution (e.g., 450 vs $364 \mathrm{kcal} /$ day/capita at 95th quantile; $p<0.05)$. In addition, although heterogenity patterns in absolute reductions for all racial/ethnic groups mimicked that of the general U.S. population, NHB households made larger reductions than NHW households at all quantiles, with larger differences toward higher quantiles (e.g., $195 \mathrm{vs} 125 \mathrm{kcal} /$ day/capita at 95th quantile; $p<0.05$ ) (Appendix Figure 2A, available online).

Comparing the magnitudes of relative reductions between NHB and NHW households along the distribution indicated that NHB households made larger relative reductions as well $(p<0.05)$ (Appendix Figure 2C, available online), leading to smaller disparities in total SSB purchases of NHB and NHW households within the top quartile of the distribution. For instance, in 2002-2003, NHB households at 95th quantile purchased around 1.24 times as many SSB calories as compared with NHW households (450 vs $364 \mathrm{kcal} /$ day/capita). In 2013-2014, this ratio was approximately 1.07 (256 vs $239 \mathrm{kcal} /$ day/ capita). However, differences between total SSB reductions of Hispanic and NHW households in both absolute and relative terms were statistically indistinguishable (Appendix Figure 2B and D, available online). This pattern was not unexpected given that these subpopulations purchased similar amounts of SSBs at baseline (e.g., 352 vs $364 \mathrm{kcal} /$ day/capita at 95th quantile) (Figure 2).

With respect to baseline disparities in SSB subtype purchases, NHBs purchased a similar number of RCSD calories to NHW households (e.g., $218 \mathrm{vs} 222 \mathrm{kcal} /$ day/capita at 95th quantile) (Appendix Figure 3, available online) but more than Hispanic households (e.g., 218 vs $175 \mathrm{kcal} /$ day/ capita at 95th quantile; $p<0.05)$. They also purchased (slightly) more fruit/sports/energy drink calories than NHW and Hispanic households across the distribution $(p<0.05)$ (Appendix Figure 4, available online). Results further indicated that all racial/ethnic groups significantly reduced their purchases of RCSD and fruit/sports/energy drinks at all quantiles, with NHB making larger absolute reductions than NHW households in both RCSD and fruit/sports/energy drink purchases $(p<0.05)$ (Appendix Figures $5 \mathrm{~A}$ and $6 \mathrm{~A}$, available online). In relative terms, NHB households' reductions in RCSDs were also larger than NHW households within the top quartile $(p<0.05)$ (Appendix Figure 5C, available online). This suggests that improvements in racial/ethnic disparities within the top quartile of total SSB distribution were likely driven by NHBs' large reductions in RCSD purchases.

Trends across the total SSB purchase distribution by household income are shown in Figure 3. First, lowincome households purchased more SSBs than highincome households in 2002-2003 $(p<0.05)$, with larger differences among high purchasers (top panels). 


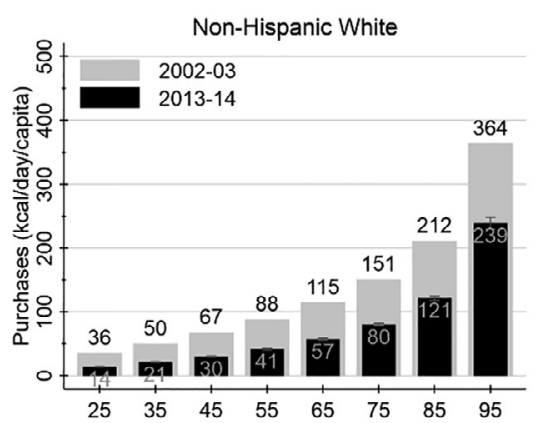

Total Sugar-Sweetened Beverages
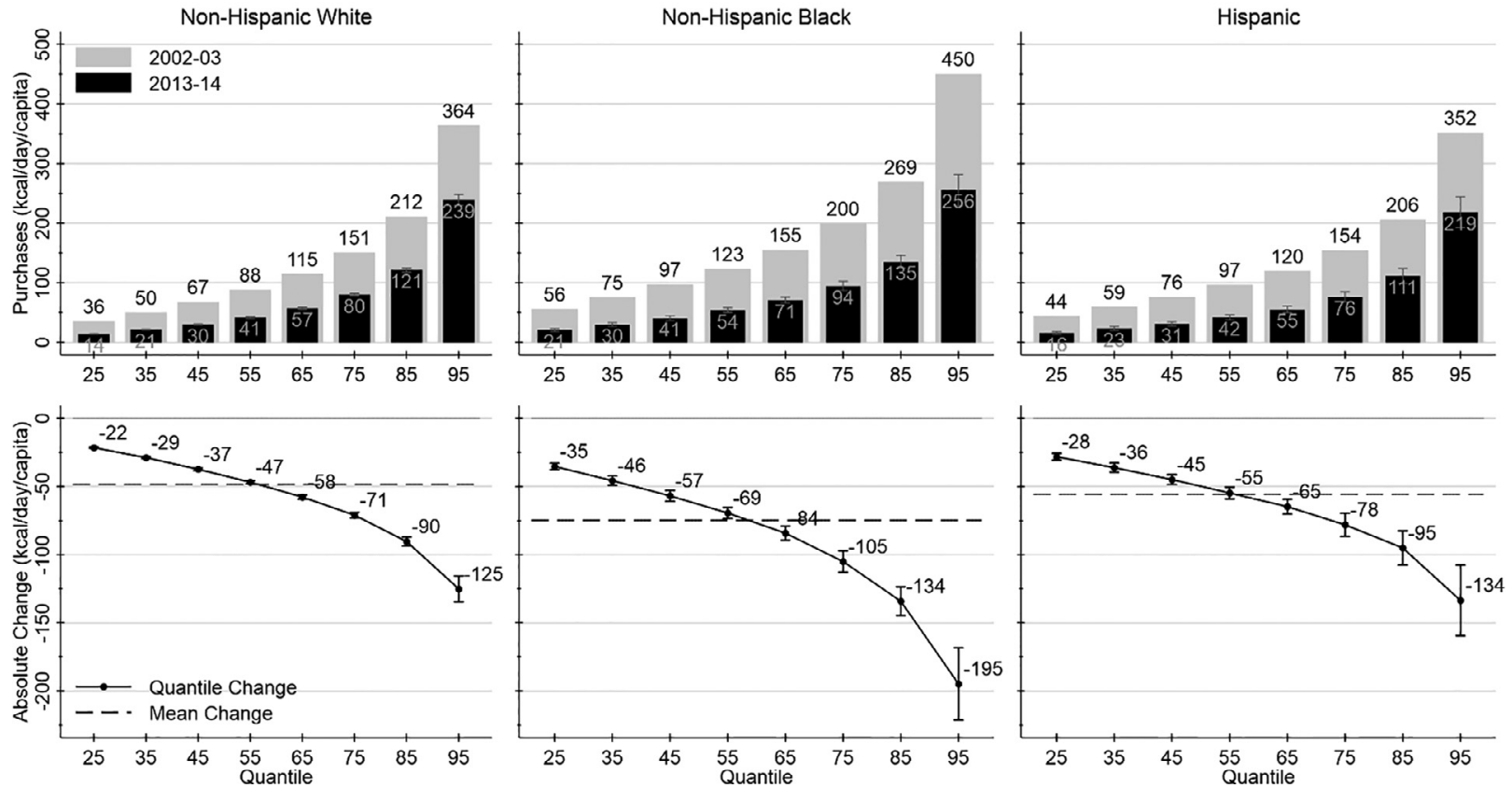

Figure 2. Trends across the adjusted distribution of total SSB purchases by race or ethnicity from 2002-2003 to 2013-2014.

Source: Authors' calculations were based, in part, on data reported by Nielsen through its Homescan Services for all food categories, including beverages and alcohol for the 2002-2014 periods across the U.S. market. ${ }^{26}$ The conclusions drawn from the Nielsen data are those of the authors and do not reflect the views of Nielsen. Nielsen is not responsible for, had no role in, and was not involved in analyzing and preparing the results reported herein.

Note: Top panels display households' total SSB purchases (kcal/day/capita) across the purchase distribution from quantiles 25th to 95th in 10-unit increments in 2002-2003 and 2013-2014. Bottom panels show the absolute quantile reductions (solid lines) and mean reduction (dashed lines) in total SSB purchases (kcal/day/capita) from 2002-2003 to 2013-2014. Survey weights were applied. All estimates are accompanied by $95 \%$ Cls calculated using SEs clustered at the household-level.

SSB, sugar-sweetened beverage.

Furthermore, results in bottom panels indicated that lowincome households made larger absolute reductions in purchases across the distribution than high-income households $(p<0.05)$ (Appendix Figure 7A, available online). However, low-income households' relative reductions were not statistically different from high-income households' relative decreases (Appendix Figure 7C, available online), implying that income disparity patterns did not improve from 2002-2003 to 2013-2014. For example, in 2002-2003, low-income households at 95th quantile purchased around 1.38 times as many SSB calories as compared with high-income households (458 vs $333 \mathrm{kcal} /$ day/capita). In 2013-2014, this ratio was still approximately 1.38 ( 287 vs $208 \mathrm{kcal} /$ day/capita).

Regarding income disparities in RCSD purchases at baseline, low-income households purchased more RCSDs than their high-income counterparts at all quantiles $(p<0.05)$ (Appendix Figure 8, available online). The magnitudes of relative reductions in RCSD purchases were not statistically different between low- and high-income households (Appendix Figure 9C, available online), suggesting that baseline disparity patterns in RCSD purchases persisted to 2013-2014. Lastly, all income groups purchased a similar number of fruit/sports/energy drink calories at baseline (Appendix Figure 10, available online) and made similar reductions in purchases in both absolute and relative terms from 2002-2003 to 2013-2014 (Appendix Figure 11, available online).

\section{DISCUSSION}

This study explored trends in SSB purchases of low- to high-SSB purchasing households across distributions of total SSB purchases and 2 key SSB subtypes (RCSDs and fruit/sports/energy drinks) in the U.S. during 2002 -2014 . Within the general U.S. population, meaningful reductions occurred in total SSB purchases at all purchase levels in both absolute and relative terms. However, magnitudes of reductions varied by purchase level, consistent with a recent study. ${ }^{13}$ In relative terms, high 

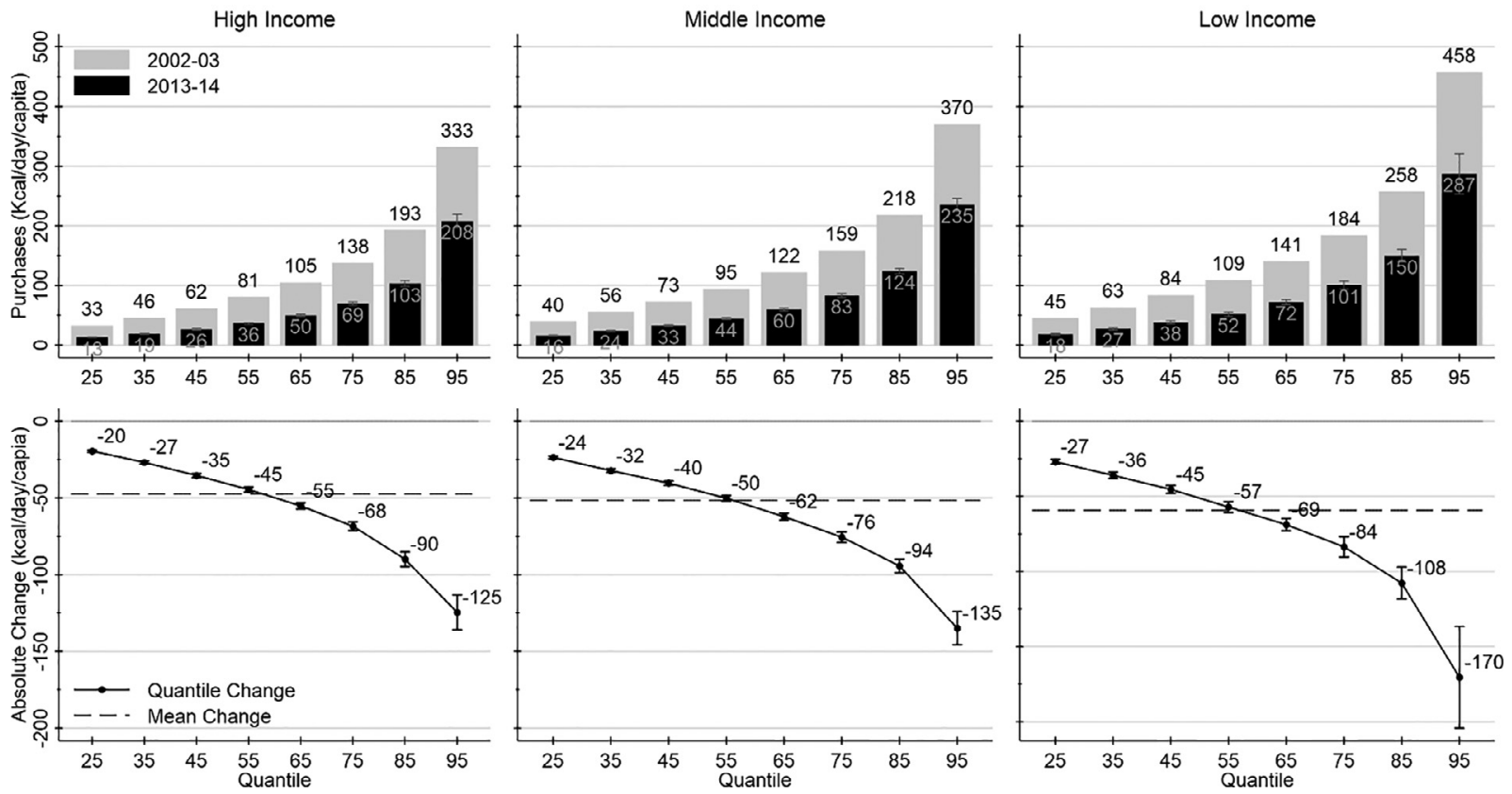

Figure 3. Trends across the adjusted distribution of total SSB purchases by income from 2002-2003 to 2013-2014.

Source: Authors' calculations were based, in part, on data reported by Nielsen through its Homescan Services for all food categories, including beverages and alcohol for the 2002-2014 periods across the U.S. market. ${ }^{26}$ The conclusions drawn from the Nielsen data are those of the authors and do not reflect the views of Nielsen. Nielsen is not responsible for, had no role in, and was not involved in analyzing and preparing the results reported herein.

Note: Top panels display households' total SSB purchases (kcal/day/capita) across the purchase distribution from quantiles 25th to 95th in 10-unit increments in 2002-2003 and 2013-2014. Bottom panels show the absolute quantile reductions (solid lines) and mean reduction (dashed lines) in total SSB purchases (kcal/day/capita) from 2002-2003 to 2013-2014. Survey weights were applied. All estimates are accompanied by 95\% Cls calculated using SEs clustered at the household-level.

SSB, sugar-sweetened beverage.

purchasers reduced their total SSB purchases less than low purchasers. In absolute terms, they made larger reductions. Similar patterns in heterogeneity were observed along SSB subtype distributions and across racial/ethnic and income subpopulations, suggesting that reductions in total SSB purchases were driven by both of its key subcategories and by all racial/ethnic and income groups.

From a public health perspective, decreases along SSB purchase distributions, particularly larger absolute reductions among high purchasers, are encouraging as excessive SSB consumption is associated with increased risks of obesity and diet-related noncommunicable diseases. ${ }^{1-7}$ SSBs are simple carbohydrates that are metabolized quickly but do not invoke a feeling of satiety, likely leading to higher overall calorie intake and thus weight gain. ${ }^{1,2,40,41}$ U.S. obesity trend studies found that after a rapid growth from the early 1980s to early 2000s, the rate of increase in obesity prevalence has slowed down recently, ${ }^{14,42-44}$ which might be partially due to overall reductions in SSB calorie purchases, particularly among higher consumers.

The second component of this study was around racial/ ethnic and income disparities in SSB purchases. The subpopulation analyses, consistent with SSB consumption literature, ${ }^{13,20}$ revealed significant racial/ethnic and income disparities in total SSB purchases in 2002-2003. In particular, NHB and low-income households purchased more SSB calories than NHW and high-income households, respectively, at all points across the total SSB purchase distribution. Furthermore, results suggested that although disparity patterns between NHB and NHW households improved among high-SSB purchasers over time (likely driven by NHBs' large reductions in RCSD purchases), income disparity patterns persisted from 2002-2003 to 2013-2014. These results echo the research on U.S. obesity trends, indicating that SES disparities have not improved in the past decade. ${ }^{45,46}$

Given that SSB prices have been declining over time, ${ }^{47}$ reductions in SSB purchases are likely due to agentic 
interventions (e.g., educational healthy eating and behavior campaigns implemented at schools/workplaces or through the mass media) intended at increasing individuals' nutritional knowledge/skills to make healthier food choices and engage in healthier behaviors. Though such interventions can be effective in obesity prevention, they are also likely to inadvertently exacerbate socioeconomic inequalities in obesity because low-SES communities have fewer economic and social resources to maximize their uptake of them. ${ }^{48-50}$ In addition, marketing strategies promoting higher intakes of caloriedense, low-nutrient foods/beverages such as fast foods and SSBs, are disproportionately targeting low-income racial/ethnic minorities and thus, directly contributing to obesity disparities affecting these subpopulations. ${ }^{51}$ ${ }^{-53}$ Extensive efforts restricting targeted unhealthy food/ beverage marketing strategies could help reduce dietrelated health disparities, including obesity, among disadvantaged communities.

Moreover, agento-structural interventions (e.g., fiscal policies) implemented at the local, state, and national level are projected to have equal or even greater benefits among low-SES groups given their wider reach and more sustained benefits, ${ }^{48-50}$ suggesting the potential for SSB taxation to reduce disparities and purchase/consumption among high purchasers/consumers. Results from Mexico's volume-based SSB tax showed much larger SSB reductions among high-SSB purchasers. ${ }^{54,55}$ Similarly, a U.S.-based study (policy simulation) also found that specific excise SSB taxes could lead to larger absolute reductions in SSB purchases of high-SSB purchasers (PV and SWN, unpublished data, 2019).

\section{Limitations}

One limitation of this study is that Homescan data reflect household-level SSB purchases and not individual-level consumption. SSB purchases could differ from SSB consumption as households might throw or give away SSBs. More importantly, Homescan only tracks packaged/pre-made SSBs purchased by households for at-home consumption and does not cover the on-the-go segment of the market, including SSBs purchased at restaurants, fast food eateries, or vending machines. One study using dietary intake data revealed that, on average, individuals (regardless of income, race, or ethnicity) acquire approximately $25 \%$ of their total beverage calories from nonstore sources. ${ }^{35}$ However, these are likely offset by this study's ability to conduct analyses over an entire year of purchases rather than 1 or 2 days of dietary recall. Moreover, relying on SSB purchases over a longer period likely helps avoid potential issues associated with using short-term self-reported intake data, such as episodic SSB consumption and under-reporting. ${ }^{56-60}$

\section{CONCLUSIONS}

Overall, though results from this study indicate that there are declining trends in SSB purchases at all purchase levels, they highlight the need for public health efforts and interventions (e.g., SSB taxation) to further reduce SSB purchases, particularly among high consumers. Furthermore, comprehensive healthy eating/behavior mass media campaigns, augmented by targeted policies focusing on reducing racial/ethnic and income disparities in SSB consumption, continue to be an important strategy to address high rates of obesity in an equitable manner.

\section{ACKNOWLEDGMENTS}

The authors thank Donna Miles for exceptional assistance with data management. The opinions and conclusions expressed herein are solely those of the authors and should not be construed as representing the opinions or policies of their institutions and the funding agencies.

This study was supported by funding from the Laura and John Arnold Foundation and used data on the basis of earlier funding from the NIH (R01DK098072, DK056350, Carolina Population Center [P2C HD050924], and T32 HD007168) and Robert Wood Johnson Foundation (71837).

The authors' responsibilities were as follows: Dr. Valizadeh conducted the research, analyzed the data, and drafted the manuscript and had primary responsibility for final content. All authors were involved in designing the research, writing the manuscript, and reading and approving the final manuscript.

No financial disclosures were reported by the authors of this paper.

\section{SUPPLEMENTAL MATERIAL}

Supplemental materials associated with this article can be found in the online version at https://doi.org/10.1016/j. amepre.2020.02.002.

\section{REFERENCES}

1. DiMeglio DP, Mattes RD. Liquid versus solid carbohydrate: effects on food intake and body weight. Int J Obes Relat Metab Disord. 2000;24 (6):794-800. https://doi.org/10.1038/sj.ijo.0801229.

2. Mourao DM, Bressan J, Campbell WW, Mattes RD. Effects of food form on appetite and energy intake in lean and obese young adults. Int J Obes (Lond). 2007;31(11):1688-1695. https://doi.org/10.1038/sj. ijo.0803667.

3. Malik VS, Popkin BM, Bray GA, Després JP, Willett WC, Hu FB. Sugar-sweetened beverages and risk of metabolic syndrome and type 2 diabetes: a meta-analysis. Diabetes Care. 2010;33(11):2477-2483. https://doi.org/10.2337/dc10-1079.

4. WHO. Guideline: Sugars Intake for Adults And children. Geneva, Switzerland: WHO; 2015. www.who.int/nutrition/publications/guidelines/sugars_intake/en/.

5. Brownell KD, Farley T, Willett WC, et al. The public health and economic benefits of taxing sugar-sweetened beverages. $N$ Engl J Med. 2009;361(16):1599-1605. https://doi.org/10.1056/NEJMhpr0905723. 
6. Malik VS, Schulze MB, Hu FB. Intake of sugar-sweetened beverages and weight gain: a systematic review. Am J Clin Nutr. 2006;84(2):274288. https://doi.org/10.1093/ajcn/84.1.274.

7. Malik VS, Pan A, Willett WC, Hu FB. Sugar-sweetened beverages and weight gain in children and adults: a systematic review and meta-analysis. Am J Clin Nutr. 2013;98(4):1084-1102. https://doi.org/10.3945/ ajcn.113.058362.

8. Hu FB, Malik VS. Sugar-sweetened beverages and risk of obesity and type 2 diabetes: epidemiologic evidence. Physiol Behav. 2010;100(1):47-54. https://doi.org/10.1016/j.physbeh.2010.01.036.

9. Welsh JA, Sharma AJ, Grellinger L, Vos MB. Consumption of added sugars is decreasing in the United States. Am J Clin Nutr. 2011;94 (3):726-734. https://doi.org/10.3945/ajcn.111.018366.

10. Reedy J, Krebs-Smith SM. Dietary sources of energy, solid fats, and added sugars among children and adolescents in the United States. $J$ Am Diet Assoc. 2010;110(10):1477-1484. https://doi.org/10.1016/j.jada. 2010.07.010.

11. Han E, Powell LM. Consumption patterns of sugar-sweetened beverages in the United States. J Acad Nutr Diet. 2013;113(1):43-53. https://doi.org/10.1016/j.jand.2012.09.016.

12. Powell ES, Smith-Taillie LP, Popkin BM. Added sugars intake across the distribution of US children and adult consumers: 1977-2012. J Acad Nutr Diet. 2016;116(10). 1543-1550.e1 https://doi.org/10.1016/ j.jand.2016.06.003.

13. Mendez MA, Miles DR, Poti JM, Sotres-Alvarez D, Popkin BM. Persistent disparities over time in the distribution of sugar-sweetened beverage intake among children in the United States. Am J Clin Nutr. 2019;109(1):79-89. https://doi.org/10.1093/ajcn/nqy123.

14. Singh GK. Trends and contemporary racial/ethnic and socioeconomic disparities in US childhood obesity. In: Bagchi D, editor. Global Perspectives on Childhood Obesity. 2nd ed London, UK: Academic Press, 2019:79-94. https://doi.org/10.1016/b978-0-12-812840-4.00007-4.

15. Brownell KD, Frieden TR. Ounces of prevention-the public policy case for taxes on sugared beverages. N Engl J Med. 2009;360(18):1805-1808. https://doi.org/10.1056/NEJMp0902392.

16. Hsiao A, Wang YC. Reducing sugar-sweetened beverage consumption: evidence, policies, and economics. Curr Obes Rep. 2013;2(3):191-199. https://doi.org/10.1007/s13679-013-0065-8.

17. Vargas-Garcia EJ, El Evans C, Cade JE. Impact of interventions to reduce sugar-sweetened beverage intake in children and adults: a protocol for a systematic review and meta-analysis. Syst Rev. 2015;4:17. https://doi.org/10.1186/s13643-015-0008-4

18. Levy DT, Friend KB, Wang YC. A review of the literature on policies directed at the youth consumption of sugar sweetened beverages. $A d v$ Nutr. 2011;2(2):182S-200S. https://doi.org/10.3945/an.111.000356.

19. Kit BK, Fakhouri TH, Park S, Nielsen SJ, Ogden CL. Trends in sugarsweetened beverage consumption among youth and adults in the United States: 1999-2010. Am J Clin Nutr. 2013;98(1):180-188. https://doi.org/10.3945/ajcn.112.057943.

20. Bleich SN, Vercammen KA, Koma JW, Li Z. Trends in beverage consumption among children and adults, 2003-2014. Obesity (Silver Spring). 2018;26(2):432-441. https://doi.org/10.1002/oby.22056.

21. Piernas C, Ng SW, Popkin B. Trends in purchases and intake of foods and beverages containing caloric and low-calorie sweeteners over the last decade in the United States. Pediatr Obes. 2013;8(4):294-306. https://doi.org/10.1111/j.2047-6310.2013.00153.x.

22. Ng SW, Slining MM, Popkin BM. Turning point for US diets? Recessionary effects or behavioral shifts in foods purchased and consumed. Am J Clin Nutr. 2014;99(3):609-616. https://doi.org/10.3945/ajcn.113.072892.

23. Bleich SN, Wolfson JA. Trends in SSBs and snack consumption among children by age, body weight, and race/ethnicity. Obesity (Silver Spring). 2015;23(5):1039-1046. https://doi.org/10.1002/oby.21050.

24. Abrevaya J, Dahl CM. The effects of birth inputs on birthweight: evidence from quantile estimation on panel data. J Bus Econ Stat. 2008;26(4):379-397. https://doi.org/10.1198/073500107000000269.
25. Bache SHM, Dahl CM, Kristensen JT. Headlights on tobacco road to low birthweight outcomes. Empir Econ. 2013;44:1593-1633. https:// doi.org/10.1007/s00181-012-0570-8.

26. The Nielsen Company. www.nielsen.com/us/en.html. Accessed June 6, 2019.

27. Einav L, Leibtag E, Nevo A. Recording discrepancies in Nielsen Homescan data: are they present and do they matter. Quant Mark Econ. 2010;8:207-239. https://doi.org/10.1007/s11129-009-9073-0.

28. Todd JE, Mancino L, Leibtag ES, Tripodo C. Methodology behind the quarterly food-at-home price database. U.S. Department of Agriculture, Economic Research Service (ERS-NASS); https://ageconsearch.umn. edu/record/97799/files/TB1926.pdf. Published 2010. Accessed April 15, 2020.

29. Zhen C, Taylor JL, Muth MK, Leibtag E. Understanding differences in self-reported expenditures between household scanner data and diary survey data: a comparison of homescan and consumer expenditure survey. Appl Econ Perspect Policy. 2009;31(3):470-492. https://doi.org/ 10.1111/j.1467-9353.2009.01449.x.

30. Zhen C, Wohlgenant MK, Karns S, Kaufman P. Habit formation and demand for sugar-sweetened beverages. Am J Agric Econ. 2011;93 (1):175-193. https://doi.org/10.1093/ajae/aaq155.

31. Zhen C, Finkelstein EA, Nonnemaker JM, Karns SA, Todd JE. Predicting the effects of sugar-sweetened beverage taxes on food and beverage demand in a large demand system. Am J Agric Econ. 2014;96(1):1-25. https://doi.org/10.1093/ajae/aat049.

32. Aguiar M, Hurst E. Life-cycle prices and production. Am Econ Rev. 2007;97(5):1533-1559. https://doi.org/10.1257/aer.97.5.1533.

33. Lusk JL, Brooks K. Who participates in household scanning panels. Am J Agric Econ. 2011;93(1):226-240. https://doi.org/10.1093/ajae/aaq123.

34. Mintel GNPD Global New Products: Tracked, Analyzed, Explained. www.mintel.com/global-new-products-database. Accessed June 6, 2019.

35. Ng SW, Poti JM, Popkin BM. Trends in racial/ethnic and income disparities in foods and beverages consumed and purchased from stores among US households with children, 2000-2013. Am J Clin Nutr. 2016;104(3):750-759. https://doi.org/10.3945/ajcn.115.127944.

36. Koenker R, Bassett G Jr. Regression quantiles. Econometrica. 1978;46 (1):33-50. https://doi.org/10.2307/1913643.

37. Koenker R, Hallock KF. Quantile regression. J Econ Perspect. 2001;15 (4):143-156. https://doi.org/10.1257/jep.15.4.143.

38. Cade BS, Noon BR. A gentle introduction to quantile regression for ecologists. Front Ecol Environ. 2003;1(8):412-420. https://doi.org/ 10.1890/1540-9295(2003)001.

39. Mundlak Y. On the pooling of time series and cross section data Econometrica. 1978;46(1):69-85. https://doi.org/10.2307/1913646.

40. Rolls BJ, Kim S, Fedoroff IC. Effects of drinks sweetened with sucrose or aspartame on hunger, thirst and food intake in men. Physiol Behav. 1990;48(1):19-26. https://doi.org/10.1016/0031-9384(90)90254-2.

41. DellaValle DM, Roe LS, Rolls BJ. Does the consumption of caloric and non-caloric beverages with a meal affect energy intake. Appetite. 2005;44(2):187-193. https://doi.org/10.1016/j.appet.2004.11.003.

42. Hales CM, Fryar CD, Carroll MD, Freedman DS, Ogden CL. Trends in obesity and severe obesity prevalence in US youth and adults by sex and age, 2007-2008 to 2015-2016. JAMA. 2018;319(16):1723-1725. https://doi.org/10.1001/jama.2018.3060.

43. Ogden CL, Carroll MD, Lawman HG, et al. Trends in obesity prevalence among children and adolescents in the United States, 1988-1994 through 2013-2014. JAMA. 2016;315(21):2292-2299. https://doi.org/ 10.1001/jama.2016.6361.

44. Anderson PM, Butcher KF, Schanzenbach DW. Understanding recent trends in childhood obesity in the United States. Econ Hum Biol. 2019;34:16-25. https://doi.org/10.1016/j.ehb.2019.02.002.

45. Rossen LM, Schoendorf KC. Measuring health disparities: trends in racial-ethnic and socioeconomic disparities in obesity among 2- to 18year old youth in the United States, 2001-2010. Ann Epidemiol. 2012;22 (10):698-704. https://doi.org/10.1016/j.annepidem.2012.07.005. 
46. Frederick CB, Snellman K, Putnam RD. Increasing socioeconomic disparities in adolescent obesity. Proc Natl Acad Sci U S A. 2014;111 (4):1338-1342. https://doi.org/10.1073/pnas.1321355110.

47. Powell LM, Chriqui JF, Khan T, Wada R, Chaloupka FJ. Assessing the potential effectiveness of food and beverage taxes and subsidies for improving public health: a systematic review of prices, demand and body weight outcomes. Obes Rev. 2013;14(2):110-128. https://doi.org/ 10.1111/obr.12002.

48. Backholer K, Beauchamp A, Ball K, et al. A framework for evaluating the impact of obesity prevention strategies on socioeconomic inequalities in weight. Am J Public Health. 2014;104(10):e43-e50. https://doi.org/ 10.2105/AJPH.2014.302066.

49. Olstad DL, Teychenne M, Minaker LM, et al. Can policy ameliorate socioeconomic inequities in obesity and obesity-related behaviours? A systematic review of the impact of universal policies on adults and children. Obes Rev. 2016;17(12):1198-1217. https://doi.org/10.1111/ obr.12457.

50. McGill R, Anwar E, Orton L, et al. Are interventions to promote healthy eating equally effective for all? Systematic review of socioeconomic inequalities in impact. BMC Public Health. 2015;15:457. https://doi.org/10.1186/s12889-015-1781-7.

51. Harris JL, Shehan C, Gross R, et al. Food advertising targeted to Hispanic and Black youth: contributing to health disparities. Rudd Center for Food Policy \& Obesity; August 2015. www.uconnruddcenter.org/ files/Pdfs/272-7\%20\%20Rudd_Targeted\%20Marketing\%20Report_ Release_081115\%5B1\%5D.pdf . Published August 2015. Accessed March 3, 2020.

52. Harris JL, Frazier W III, Kumanyika S, Ramirez AG. Increasing disparities in unhealthy food advertising targeted to Hispanic and black youth. Rudd Center for Food Policy \& Obesity; January 2019. http:// uconnruddcenter.org/files/Pdfs/TargetedMarketingReport2019.pdf. Published January 2019. Accessed March 3, 2020.
53. Herrera AL, Pasch KE. Targeting Hispanic adolescents with outdoor food \& beverage advertising around schools. Ethn Health. 2018;23 (6):691-702. https://doi.org/10.1080/13557858.2017.1290217.

54. Ng SW, Rivera JA, Popkin BM, Colchero MA. Did high sugar-sweetened beverage purchasers respond differently to the excise tax on sugar-sweetened beverages in Mexico. Public Health Nutr. 2019;22 (4):750-756. https://doi.org/10.1017/S136898001800321X.

55. Taillie LS, Rivera JA, Popkin BM, Batis C. Do high vs. low purchasers respond differently to a nonessential energy-dense food tax? Twoyear evaluation of Mexico's 8\% nonessential food tax. Prev Med. 2017;105(suppl):S37-S42. https://doi.org/10.1016/j.ypmed.2017.07.009.

56. Castro-Quezada I, Ruano-Rodríguez C, Ribas-Barba L, Serra-Majem L. Misreporting in nutritional surveys: methodological implications. Nutr Hosp. 2015;31(suppl 3):119-127. https://doi.org/10.3305/nh.2015. 31.sup3.8760.

57. Yanetz R, Kipnis V, Carroll RJ, et al. Using biomarker data to adjust estimates of the distribution of usual intakes for misreporting: application to energy intake in the US population. J Am Diet Assoc. 2008;108 (3):455-464. [discussion 464]. https://doi.org/10.1016/j.jada.2007.12. 004.

58. Westerterp KR, Goris AH. Validity of the assessment of dietary intake: problems of misreporting. Curr Opin Clin Nutr Metab Care. 2002;5 (5):489-493. https://doi.org/10.1097/00075197-200209000-00006.

59. Krebs-Smith SM, Graubard BI, Kahle LL, Subar AF, Cleveland LE, Ballard-Barbash R. Low energy reporters vs others: a comparison of reported food intakes. Eur J Clin Nutr. 2000;54(4):281-287. https:// doi.org/10.1038/sj.ejcn.1600936.

60. Lafay L, Mennen L, Basdevant A, et al. Does energy intake underreporting involve all kinds of food or only specific food items? Results from the Fleurbaix Laventie Ville Sante (FLVS) study. Int J Obes Relat Metab Disord. 2000;24(11):1500-1506. https://doi.org/10.1038/sj. ijo.0801392. 